\title{
Stability Investigation of Ligand-Exchanged CdSe/ZnS-Y ( $Y=3$-Mercaptopropionic Acid or Mercaptosuccinic Acid) through Zeta Potential Measurements
}

\author{
Ngoc Thuy Vo, Hai Dang Ngo, Ngoc Phuong Do Thi, Kim Phung Nguyen Thi, \\ Ai Phuong Duong, and Vinh Lam \\ Department of Physics, University of Science, Vietnam National University, Ho Chi Minh City 749000, Vietnam \\ Correspondence should be addressed to Ngoc Thuy Vo; vtnthuy@hcmus.edu.vn
}

Received 25 March 2016; Accepted 1 June 2016

Academic Editor: Mikael Motelica-Heino

Copyright ( $\odot 2016$ Ngoc Thuy Vo et al. This is an open access article distributed under the Creative Commons Attribution License, which permits unrestricted use, distribution, and reproduction in any medium, provided the original work is properly cited.

Quantum dots have been considered to be promising candidates for bioapplications because of their high sensitivity, rapid response, and reliability. The synthesis of high-quality quantum dots that can be dissolved in water and other biological media is a crucial step toward their further application in biology. Starting with a one-pot reaction and the successive ionic layer adsorption and reaction (SILAR) method, we produced the CdSe/ZnS core/shell structure. Through a ligand-exchange mechanism, we coated the asmade CdSe/ZnS structure with 3-mercaptopropionic acid (MPA) or mercaptosuccinic acid (MSA). Various techniques, including photoluminescence (PL), ultraviolet-visible (UV-Vis) spectroscopy, transmission electron microscopy (TEM), X-ray diffraction (XRD), and Fourier transform infrared (FTIR) spectroscopy, were utilized to characterize the ligand-coated CdSe/ZnS structure. The results show enhanced luminescence intensity, CdSe surface passivation by ZnS, and successful coating with MPA and MSA. The stability of quantum dots in solutions with different $\mathrm{pH}$ values was investigated by performing zeta potential measurements. The results revealed that the quantum dots shifted from displaying hydrophobic to hydrophilic behavior and could be connected with bioagents.

\section{Introduction}

Semiconducting quantum dots have been extensively studied in recent decades because of their unique physical characteristics, which are superior to those of their bulk and thin-film counterparts. In the II-VI semiconductor class of compounds, CdSe has been the most thoroughly researched material for both synthesis and application. CdSe quantum dots have been intensely investigated and applied in many different fields, including display devices, quantum dot solar cells, quantum dot lasers, and biological applications. Because of their high photostability, low photobleaching speed, and strong photoluminescence (PL) under illumination, they have great potential to replace the currently used organic dyes and are also good candidate materials for biomedical applications. Numerous scientific works related to CdSe quantum dots have been published in bioimaging and biosensing fields [1-3].
Currently, the synthesis of quantum dots from metalorganic precursors remains the most effective method for obtaining high-quality and high-luminescence nanoparticles. However, the problems of unstable organic cover layers and low quantum dot surface coverage (approximately 40$60 \%$ ) must be overcome [4]. Indeed, because of these issues, abundant defects exist at the surface that decreases the dot luminescence efficiency. Covering CdSe quantum dots with outer inorganic shells with higher band-gaps not only helps to passivate the dangling bonds at the core surface but also creates a potential barrier for electron confinement and reduces the effect of the surrounding environment. This, in turn, enhances the dots chemical stability and luminescence efficiency.

Several materials, such as CdSe $(1.74 \mathrm{eV}), \mathrm{CdS}(2.49 \mathrm{eV})$, $\mathrm{ZnSe}(2.69 \mathrm{eV})$, and $\mathrm{ZnS}(3.61 \mathrm{eV})$, are suitable for use in shell coverage. Among these, $\mathrm{ZnS}$ consists of common, earthabundant elements. ZnS outer shell would also prevent the 
leakage of $\mathrm{Cd}^{2+}$ or $\mathrm{Se}^{2-}$ ions into the surroundings, reducing the toxicity associated with quantum dots [5].

However, this CdSe/ZnS core/shell structure cannot be dissolved in water, and as a result, it cannot be applied directly in biological studies. Thus, the surfaces of these materials must be functionalized for bioapplications. This process shifts the characteristics of quantum dots from hydrophobic to hydrophilic and facilitates their connection with bioagents $[6,7]$.

There are many different approaches to achieve surface functionalization, such as the use of polymer coverage or organic fibers. Although those materials maintain the dots' hydrophobic characteristics and reduce their toxicity, their use drastically increases the particle sizes. This leads to low luminescence and reduces chemical stability. Meanwhile, ligand-exchange methods are widely used because of their simplicity and the small sizes of the final products. Mercaptopropionic acid (MPA) and mercaptosuccinic acid (MSA) molecules comprising thiol and carboxylic functional groups play highly important roles as suitable new ligands. They help to reduce the dangling bonds at the surface, prevent agglomeration, and connect the quantum dots with bioagents [8-15]. Investigating the connections between quantum dots and their surrounding molecules is extremely important, which leads to better understanding of the effect of covering molecules on the characteristics of quantum dots, especially the optical characteristics crucial for biosensing applications.

In this report, we present the synthesis and characterization of the CdSe/ZnS core/shell structure and the functionalization of its surface with MPA and MSA. The properties and structure of the quantum dots were characterized using absorption and PL spectroscopy, X-ray diffraction (XRD), transmission electron microscopy (TEM), and Fourier transform infrared spectroscopy (FTIR). We obtained high-quality $\mathrm{CdSe} / \mathrm{ZnS}$ core/shell structures with high-luminescence and suitable crystal structures. Successful ligand exchange was confirmed qualitatively and quantitatively. The durability of $\mathrm{CdSe} / \mathrm{ZnS}$, CdSe/ZnS-MPA, and CdSe/ZnS-MSA was compared using zeta potential measurements [15]. Based on these fundamental results, in the future, we aim to utilize $\mathrm{CdSe} / \mathrm{ZnS}$-ligands in bioimaging and the early biodetection of diseases.

\section{Experiment}

2.1. Fabrication of CdSe and CdSe/ZnS Quantum Dots. According to the literature [16-18], the colloidal method, a widely used approach to synthesize CdSe quantum dots, was employed for fabrication in this work. The procedure was as follows: we first dissolved $0.133 \mathrm{~g}$ of cadmium acetate dehydrates in $0.64 \mathrm{~mL}$ of oleic acid (OA) and $5 \mathrm{~mL}$ of diphenyl ether (DPE). The obtained solution was stirred continuously in nitrogen atmosphere and heated to $180^{\circ} \mathrm{C}$. Then, $0.5 \mathrm{~mL}$ of $1 \mathrm{M}$ trioctylphosphine-selenide solution (TOP-Se) $(0.66 \mathrm{~g}$ of selenium powder and $8.36 \mathrm{~mL}$ of TOP) was injected rapidly into the cadmium solution. After a certain reaction time, the final solution was cooled to room temperature, subjected to centrifugation several times, and finally dispersed in hexane or toluene for long-term preservation.
The CdSe/ZnS core/shell structure was synthesized by the successive ion layer adsorption and reaction (SILAR) method. We added $1.1 \mathrm{~mL}$ of CdSe, $0.5 \mathrm{~g}$ of octadecylamine (ODA), and $2 \mathrm{~mL}$ of octadecene (ODE) into a three-necked flask. The flask was evacuated and kept at $100^{\circ} \mathrm{C}$ in 30 minutes. Then, it was filled with nitrogen gas and heated to $150^{\circ} \mathrm{C}$. For the shell covering, $0.65 \mathrm{~mL}$ of $\mathrm{Zn}^{2+}$ and $0.13 \mathrm{~mL}$ of $\mathrm{S}^{2-}$ were injected into the flask. The reaction time was 10 minutes after each injection. The solution was then cooled to room temperature. We thus obtained $\mathrm{CdSe} / \mathrm{ZnS}$ quantum dots with core/shell structure in ODE solvent. To collect clean quantum dots, the solution was dispersed in $1 \mathrm{~mL}$ of hexane and $2 \mathrm{~mL}$ of methanol and then centrifuged at $3500 \mathrm{rpm}$ for 15 minutes. This cleaning procedure was repeated at least 3 times. The clean quantum dots were then dispersed in chloroform for preservation and subsequent surface functionalization.

\subsection{Ligand Exchange of CdSe/ZnS Quantum Dots with MPA} or MSA. After synthesis, the surfaces of the CdSe/ZnS core/shell structure quantum dots were covered with the phosphine groups of TOP molecules. These groups can be replaced by carboxyl groups in their MPA or MSA counterparts in a procedure known as ligand exchange.

We added $1 \mathrm{~mL}$ of $\mathrm{CdSe} / \mathrm{ZnS}$ dispersed in chloroform to a sealed glass bottle, followed by $1 \mathrm{~mL}$ of toluene, $5 \mu \mathrm{L}$ of MPA, and $1 \mathrm{~mL}$ of phosphate-buffered saline (PBS, $\mathrm{pH}$ 7.0). The entire solution was then stirred for 24 to 48 hours at room temperature to allow the ligand-exchange reaction to occur. The solution was then dispersed into the buffer solution $(\mathrm{pH}$ 9.0) and centrifuged at $3500 \mathrm{rpm}$ to eliminate excess MPA. Finally, CdSe/ZnS-MPA quantum dots were redispersed in the preferred buffer solution. The entire procedure was repeated for MSA with a minor modification: $5 \mu \mathrm{L}$ of MSA was added instead of $5 \mu \mathrm{L}$ of MPA.

\section{Results and Discussion}

The optical properties of $\mathrm{CdSe}$ and $\mathrm{CdSe} / \mathrm{ZnS}$ were investigated by ultraviolet-visible (UV-Vis) absorption and PL (Horiba Jobin Yvon) spectroscopy at an excitation wavelength of $325 \mathrm{~nm}$.

As shown in Figure 1, the absorption peak of the $\mathrm{CdSe} / \mathrm{ZnS}$ core/shell shifts toward longer wavelengths relative to that of the CdSe core, confirming the formation of the shell layer around the CdSe core, which increases the quantum dot mass. This, in turn, enhances the absorption capability and luminescence efficiency of the $\mathrm{CdSe} / \mathrm{ZnS}$ core/shell structure, as shown in Figure 2.

As shown in Figure 2, the PL peak of the CdSe core is located at $538 \mathrm{~nm}$; upon coating with $\mathrm{ZnS}$, the peak shifts toward longer wavelengths of $581 \mathrm{~nm}$ and $588 \mathrm{~nm}$, corresponding to the number of times SILAR repeated. The PL spectra exhibit narrow and symmetric shapes, confirming the particle size uniformity. Furthermore, the core/shell luminescence intensities are greatly improved because of the shell coating. However, as the shell thickness increases, the intensity of the two-SILAR-cycle sample was lower than that of the single-cycle case. This can be explained by the increased number of surface defects. To determine the crystal structure 


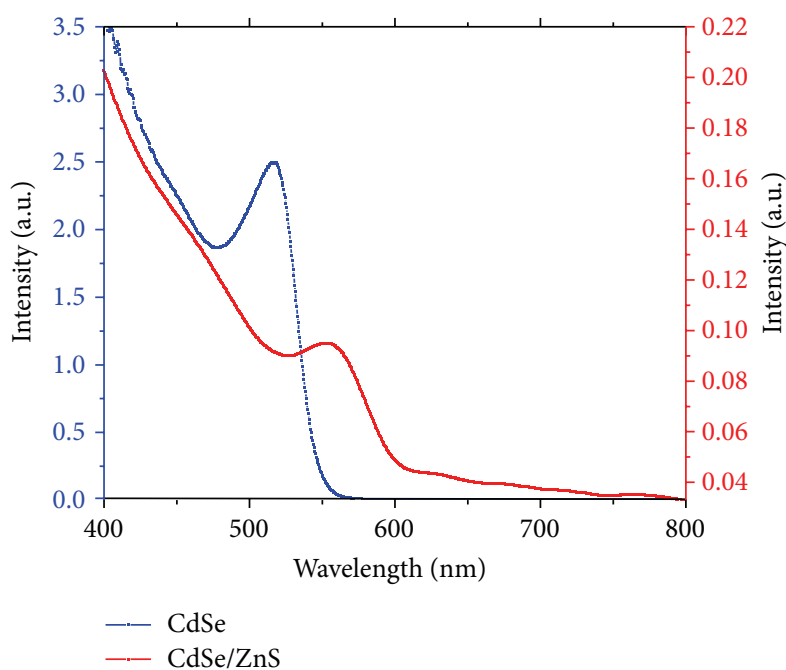

FIgUre 1: UV-Vis absorption of CdSe and CdSe/ZnS.

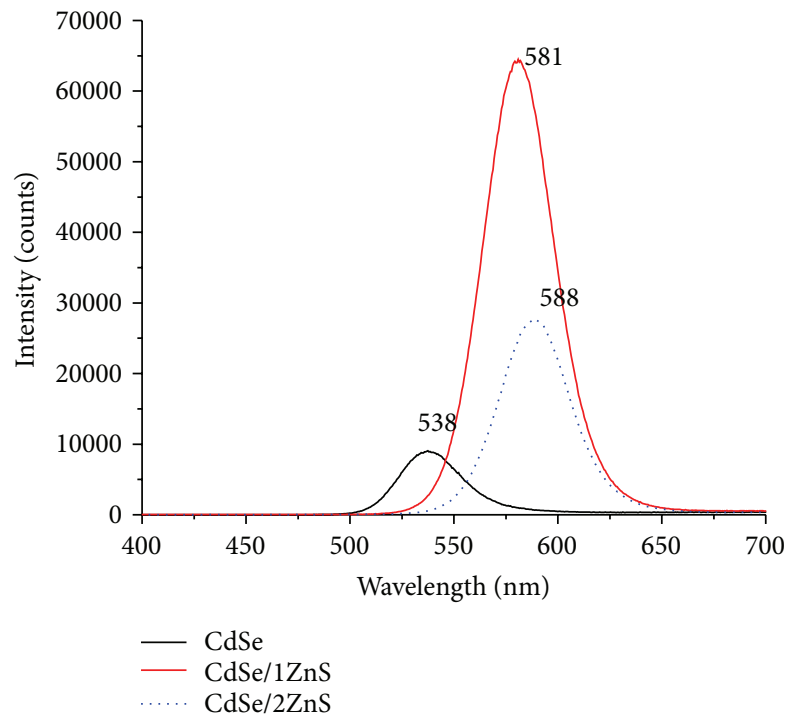

Figure 2: PL spectra of CdSe and CdSe/ZnS.

and stability of the $\mathrm{ZnS}$ layer, XRD was employed, and the results are presented in Figure 3.

Three typical peaks of the CdSe core in zinc-blende structure are evident at $25.49^{\circ}, 43.05^{\circ}$, and $49.73^{\circ}$ and correspond to the (111), (220), and (311) lattice directions, respectively. After $\mathrm{ZnS}$ coating, all the main peaks are shifted to the righthand side. As the number of layers increases, the main peaks gradually shift toward the typical $\mathrm{ZnS}$ zinc-blende structure $[4,5]$. To investigate the shape of the CdSe/ZnS particles, TEM images were obtained, as shown in Figure 4.

This image shows sphere-like particles with diameters of approximately $4.0 \mathrm{~nm}$. No anomalously large particles were found.

To examine the durability of the CdSe/ZnS quantum dots, we performed zeta potential measurements (Zeta Sizer Nano ZS, Malvern Instrument Ltd., serial number MAL1026429,

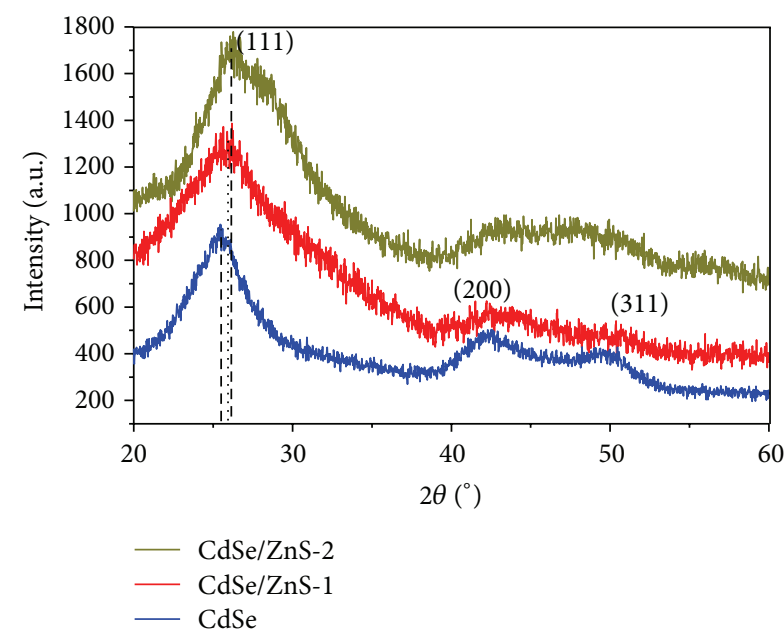

Figure 3: XRD patterns of CdSe and CdSe/ZnS quantum dots.

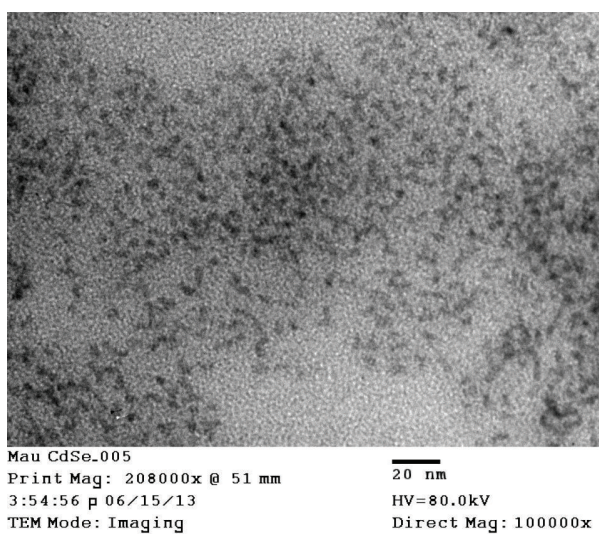

Figure 4: TEM image of $\mathrm{CdSe} / \mathrm{ZnS}$ core/shell sample coated at $130^{\circ} \mathrm{C}$.

DTS Ver. 5.10). The samples were measured in a folded capillary Cell DTS (1070) at $25^{\circ} \mathrm{C}$.

As shown in Figure 5, the value of the zeta potential is approximately $40 \mathrm{mV}$. Thus, the surfaces of the quantum dots synthesized with TOP as the surfactant are surrounded by positive ions. Additionally, the quantum dots are well dispersed in chloroform, the static repulsive force between particles is fairly strong, and more importantly, the quantum dots exhibit good durability [19-21].

Figure 6 shows the phase transformation of quantum dots before and after successful surface modification. Prior to the surface functionalization of the CdSe/ZnS quantum dots with MPA, the solution was separated into two layers: the transparent upper layer is in a polar buffer environment, whereas the lower red-orange layer consists of CdSe/ZnS quantum dots in a nonpolar solution. After surface modification, the solution separates into two layers: the colored upper layer contains CdSe/ZnS quantum dots coated with MPA, confirming the occurrence of a phase transformation in the buffer solution, whereas the transparent lower layer consists of the initial nonpolar solution of the $\mathrm{CdSe} / \mathrm{ZnS}$ quantum dots. 


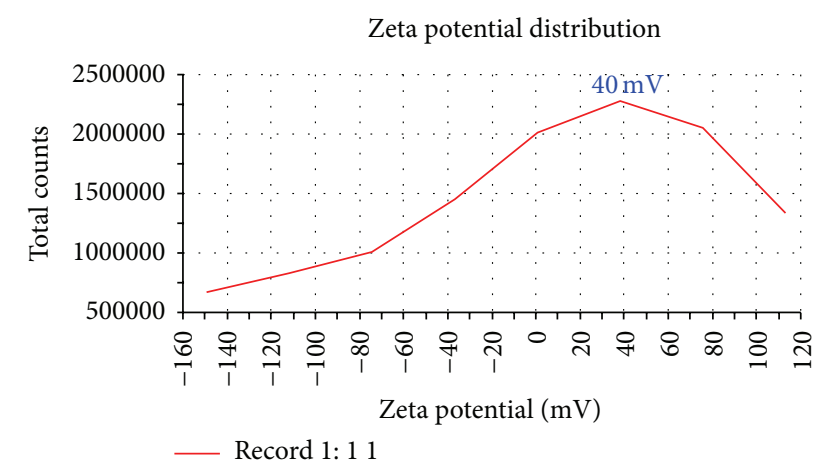

Figure 5: The zeta potential of CdSe/ZnS.

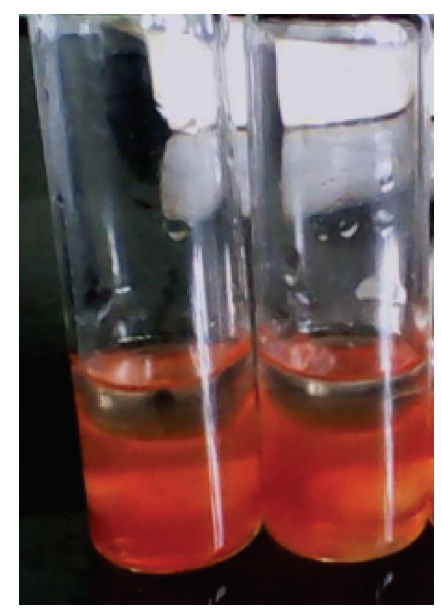

(a)

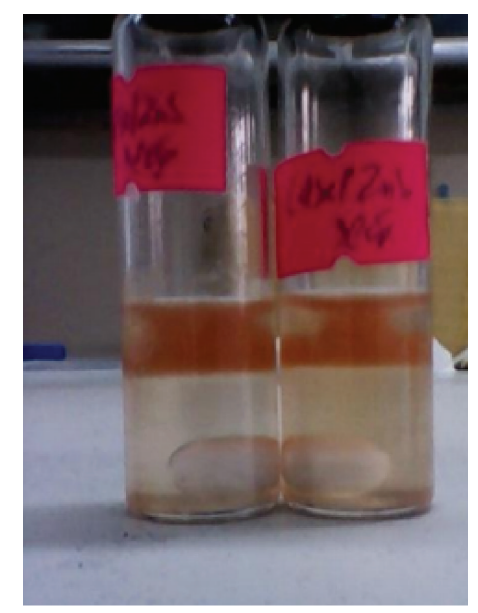

(b)

FIgURE 6: Quantum dots before (a) and after functionalization (b).

To investigate the effects of MPA and MSA ligands on the properties of quantum dots, we employed absorption and $\mathrm{PL}$ spectroscopy and TEM.

As shown in Figure 7, as the TOP molecule was replaced by MPA, the absorption peak of CdSe/ZnS-MPA moved to shorter wavelengths. This shift may be attributable to the smaller size of the MPA molecule compared with TOP. We

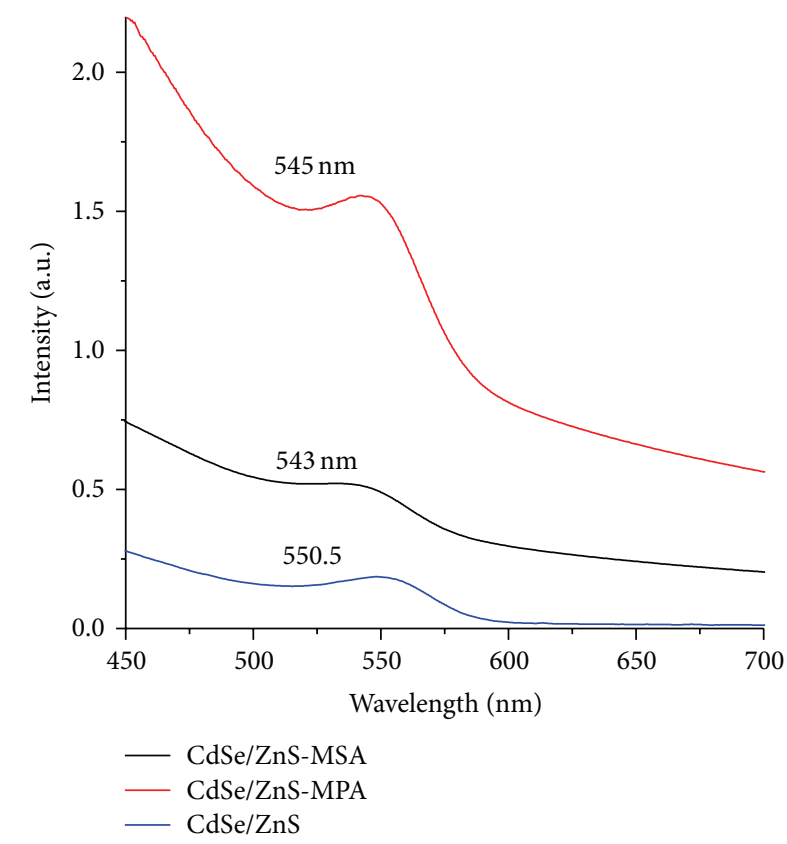

FIGURE 7: UV-Vis absorption of CdSe/ZnS after functionalization with MPA and MSA.

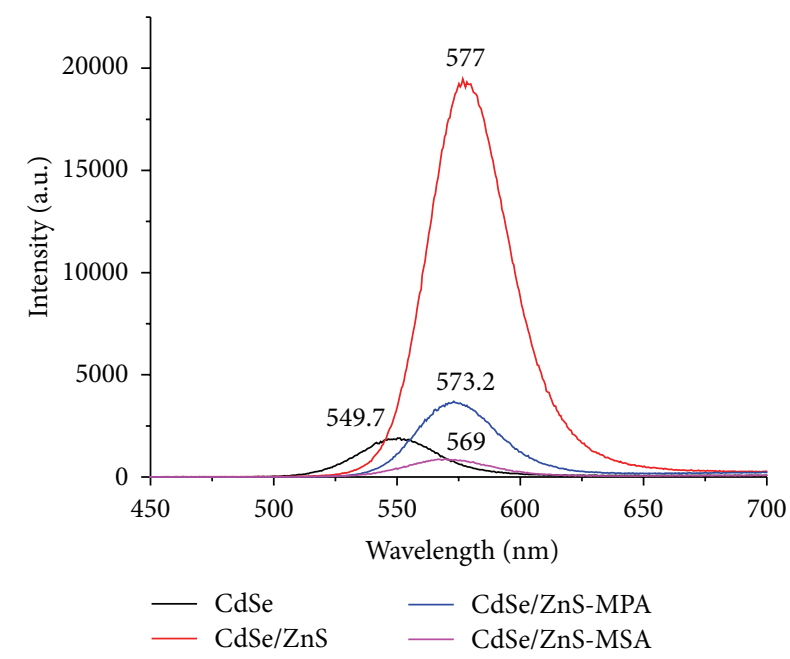

Figure 8: PL spectra of CdSe/ZnS before and after functionalization.

also observed the same shift for CdSe/ZnS-MSA. The blue shift was also observed in the PL results, as shown in Figure 8.

When TOP was replaced by MPA or MSA, the PL peaks of CdSe/ZnS-MPA (or MSA) moved to shorter wavelengths, and their intensities decreased drastically. This result matched well with report [22].

MPA-conjugated quantum dots showed better luminescence intensity than MSA-conjugated ones. Although MSA includes two carboxyl groups and has better bioconjugation capability, MPA appears to be a more suitable ligand for TOP substitution for bioapplications, such as biosensors.

The effect of the $\mathrm{pH}$ value on luminescence intensities is clearly shown in Figure 9. Compared with $\mathrm{CdSe} / \mathrm{ZnS}$, 


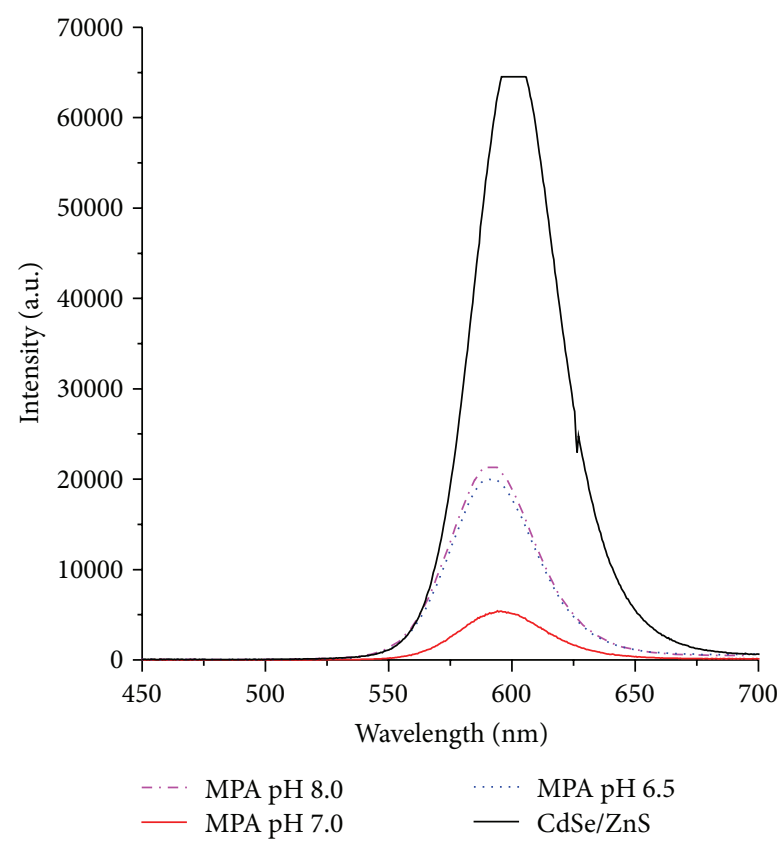

(a)

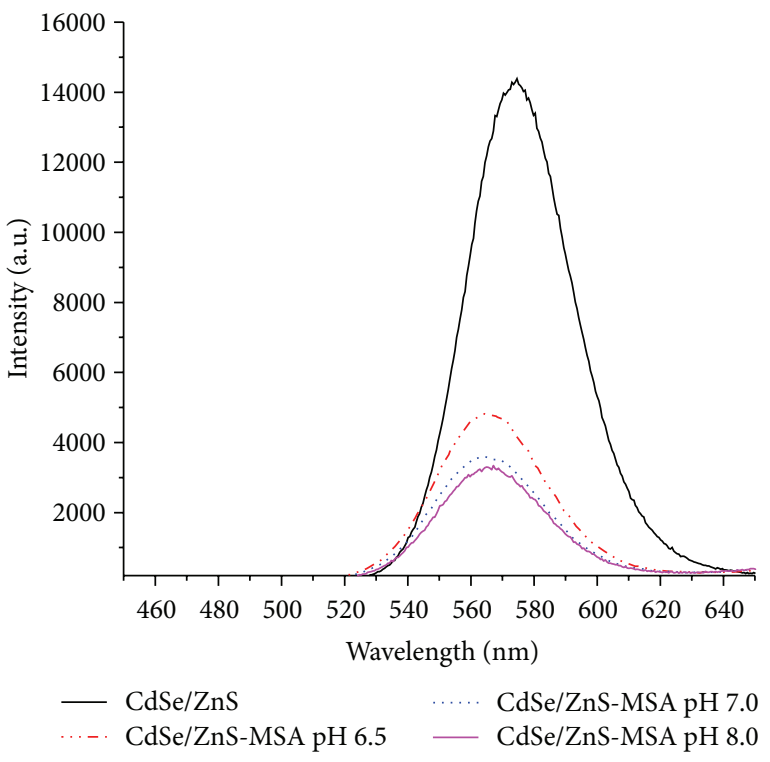

(b)

Figure 9: PL spectra of CdSe/ZnS-MPA (a) and CdSe/ZnS-MSA (b) solutions at different $\mathrm{pH}$ values.

CdSe/ZnS-MPA solutions with different $\mathrm{pH}$ values $(6.5,7.0$, and 8.0) exhibited shorter peak wavelengths and much lower $\mathrm{PL}$ intensities. Additionally, the intensity of CdSe/ZnS-MPA in neutral solution was lower than those in acidic and basic solutions. In contrast, the PL intensities decreased gradually as the $\mathrm{pH}$ value increased from 6.5 to 8.0.

The FTIR spectra of CdSe/ZnS-MPA and CdSe/ZnSMSA show three main peaks compared with CdSe/ZnS. The carboxyl groups $(-\mathrm{COOH})$ in MPA and MSA show strong absorbance at $1700 \pm 10 \mathrm{~cm}^{-1}$, demonstrating that the TOP surfactant on $\mathrm{CdSe} / \mathrm{ZnS}$ was replaced by MPA or MSA

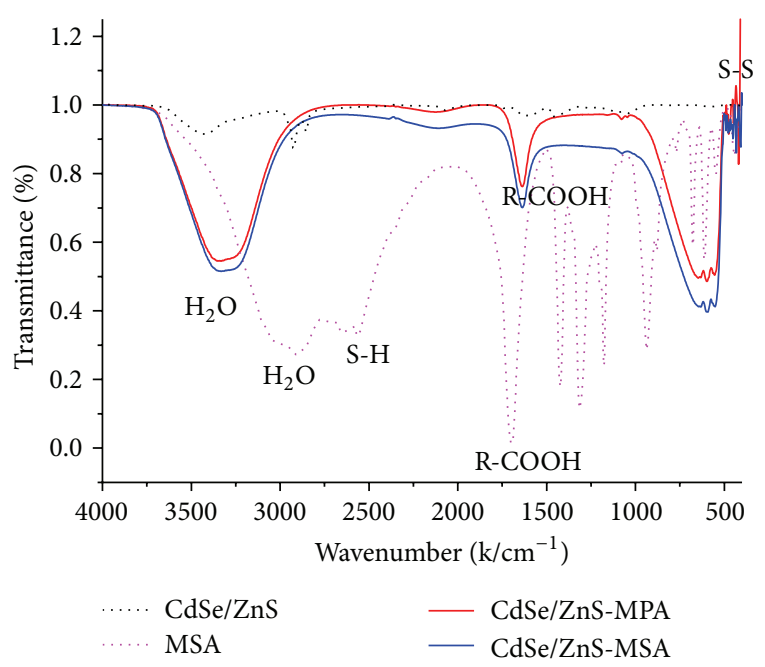

FIGURE 10: FTIR spectra of quantum dots before and after functionalization with MPA and MSA.

molecules. This ligand exchange occurs at the thiol groups ($\mathrm{SH}$ ) that are attached to $\mathrm{ZnS}$ surface through disulfide (S-S) bonds. This was confirmed by the disappearance of $1289 \mathrm{~cm}^{-1}$ peak corresponding to - $\mathrm{SH}$ bonding and the appearance of peaks in $450-500 \mathrm{~cm}^{-1}$ wavenumber range corresponding to $\mathrm{S}-\mathrm{S}$ bonding in $\mathrm{CdSe} / \mathrm{ZnS}-\mathrm{MPA}$ (or MSA) samples. Additionally, the emergence of a strong hydroxyl (-OH) group absorption peak at approximately $3303 \mathrm{~cm}^{-1}$ confirms the good dispersion of the quantum dots in water and other biological media. This ability and the existence of carboxyl groups allow CdSe/ZnS-MPA (or MSA) quantum dots to be conjugated with bioagents, enabling their application in biosensor fabrication.

Figure 10 shows the zeta potentials of CdSe/ZnS-MPA and CdSe/ZnS-MSA. Relative to that of CdSe/ZnS, after ligand exchange with MPA or MSA, the zeta potentials of the resulting materials shifted to the left-hand side, achieving values of $-34.6 \mathrm{mV}(\mathrm{CdSe} / \mathrm{ZnS}-\mathrm{MPA})$ and $-27.0 \mathrm{mV}$ (CdSe/ZnS-MSA). These values indicate that the positive ionic layers at the outer surfaces of $\mathrm{CdSe} / \mathrm{ZnS}$ were replaced by negative ionic layers and confirm that the ligand exchange was successful and that the resulting structures are highly durable. For the same quantum dot concentration and $\mathrm{pH}$ value, the absolute zeta potential of $\mathrm{CdSe} / \mathrm{ZnS}-\mathrm{MSA}$ was lower than that of CdSe/ZnS-MPA. Thus, CdSe/ZnS-MPA exhibits much better dispersion in chloroform solvent, is more durable, and is more suitable for further development for bioapplications.

The effect of the $\mathrm{pH}$ value on the quantum dot stability was investigated further. Zeta potentials were measured to obtain the potential values for $\mathrm{CdSe} / \mathrm{ZnS}-\mathrm{MPA}$ and $\mathrm{CdSe} / \mathrm{ZnS}-\mathrm{MSA}$ at different $\mathrm{pH}$ values $(6.5,7.0$, and 8.0$)$, as shown in Figures 11 and 12.

At the same concentration but different $\mathrm{pH}$ values, the quantum dot solutions show varied dispersion and diverse stabilities as depicted in Figure 13. Low $\mathrm{pH}$ values facilitate the protonation of carboxyl groups, the development of 


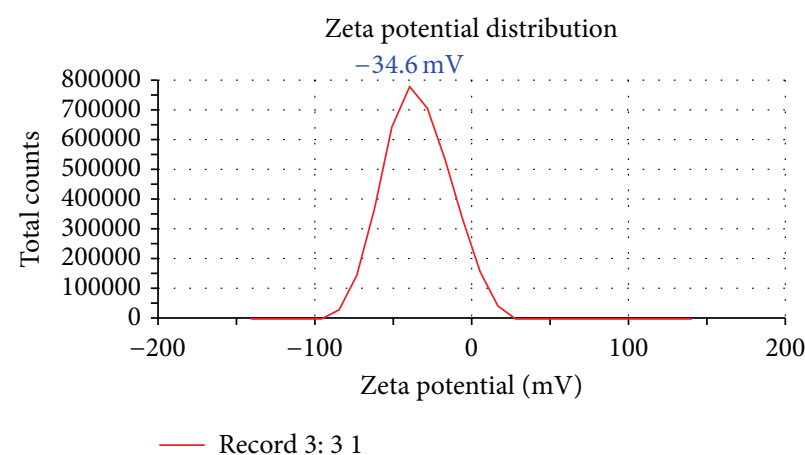

(a)

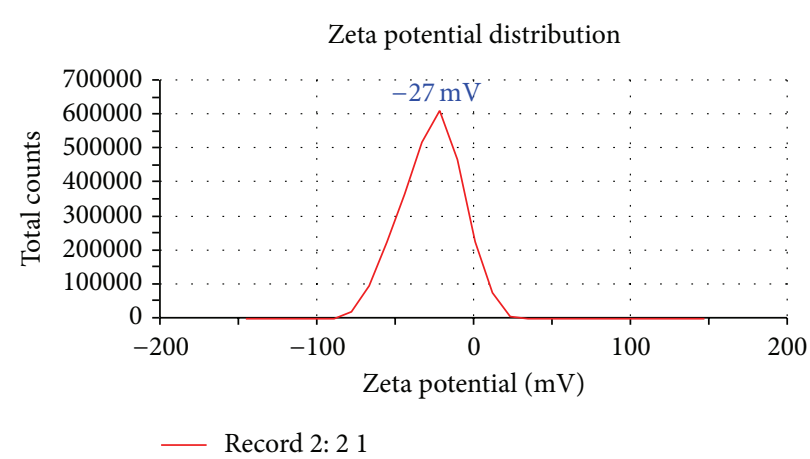

(b)

FIgUre 11: The zeta potentials of CdSe/ZnS-MPA (a) and CdSe/ZnS-MSA (b).

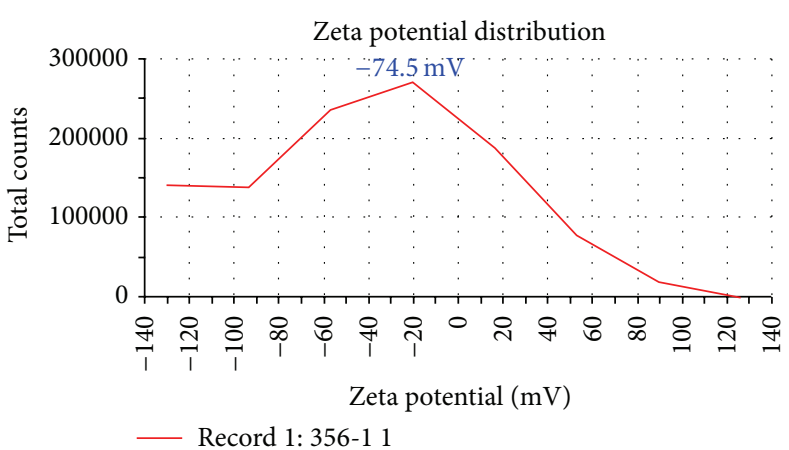

(a)

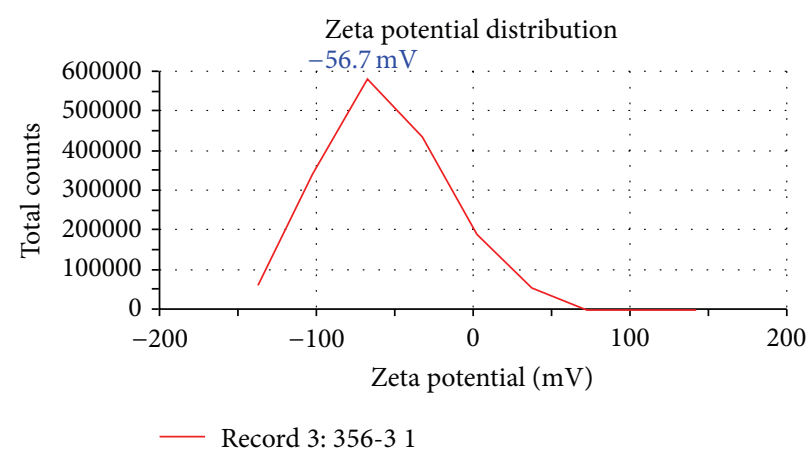

(c)

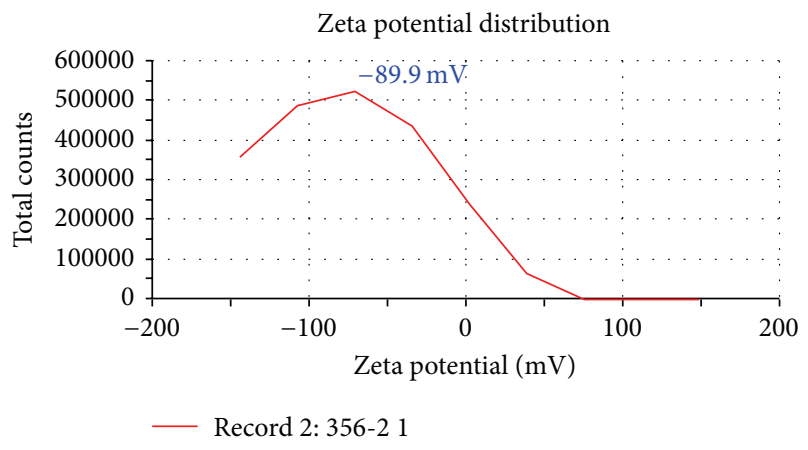

(b)

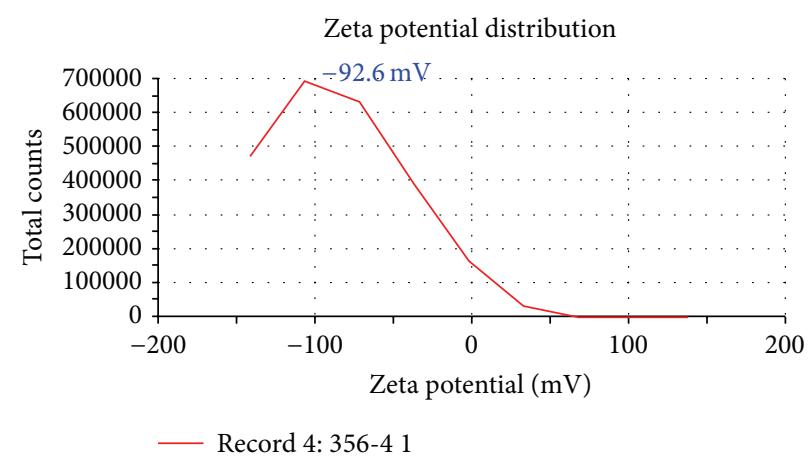

(d)

Figure 12: Zeta potentials of CdSe/ZnS-MPA at pH 6.5 (a) and pH 8.0 (b) and those of CdSe/ZnS-MSA at pH 6.5 (c) and pH 8.0 (d).

stronger interactions, and good dispersion of quantum dots in water; additionally, because of the strong repulsive force between the particles, the quantum dots exhibit very good durability. However, excessive protonation can lead to poor surface protection of the quantum dots. The low passivation of dangling bonds and the poor reduction of trapping levels can decrease the overall luminescence intensity. Based on these results, we identified $\mathrm{pH} 7.0$ as the most suitable value for quantum dot dispersion and preservation.

TEM image of CdSe/ZnS-MPA is presented in Figure 14 and shows sphere-like nanoparticles with a uniform size, which is smaller than that of the CdSe/ZnS nanoparticles shown in Figure 4. This is in good agreement with the spectroscopy results presented above.

\section{Conclusion}

We successfully synthesized CdSe/ZnS core/shell quantum dots and functionalized their surfaces by replacing the phosphine group of the TOP molecule with the carboxyl group of MPA and MSA. The properties of the synthesized quantum dots were characterized by absorption and PL spectroscopy, XRD, FTIR, and TEM. In the PL spectra, we observed the strong enhancement of luminescence efficiency of CdSe/ZnS by up to 70 times relative to that of the CdSe core. FTIR revealed the solubility of the quantum dots in water and biological media. The neutral $\mathrm{pH}$ value (7.0) resulted in the best luminescence efficiency and is the most suitable for attaching bioagents to quantum dots. Zeta potential 


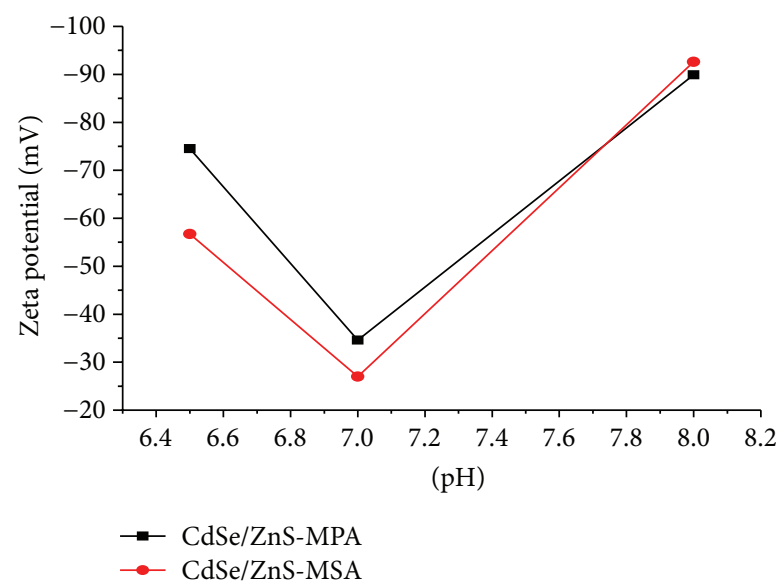

Figure 13: Variation of the zeta potentials of CdSe/ZnS-MPA and $\mathrm{CdSe} / \mathrm{ZnS}-\mathrm{MSA}$ at different $\mathrm{pH}$ values.

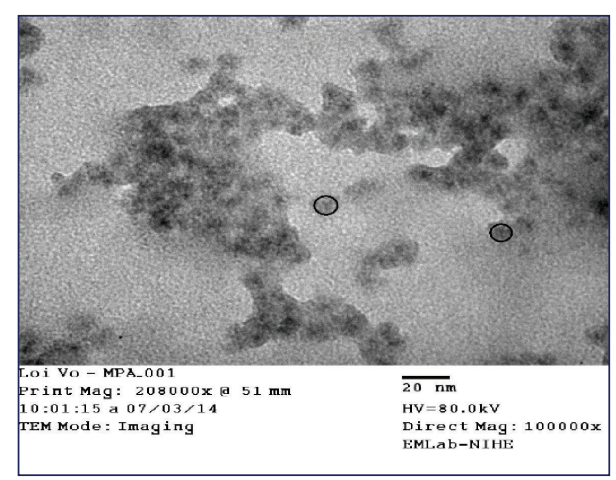

Figure 14: TEM image of CdSe/ZnS-MPA quantum dots.

measurements revealed the high stability of $\mathrm{CdSe} / \mathrm{ZnS}$ MPA and CdSe/ZnS-MSA. These results are of fundamental importance for conjugating bioagents with quantum dots for bioapplications.

\section{Competing Interests}

The authors declare that they have no competing interests.

\section{References}

[1] S. K. Mahto, C. Park, T. H. Yoon, and S. W. Rhee, "Assessment of cytocompatibility of surface-modified CdSe/ZnSe quantum dots for BALB/3T3 fibroblast cells," Toxicology in Vitro, vol. 24, no. 4, pp. 1070-1077, 2010.

[2] R. A. Sperling and W. J. Parak, "Surface modification, functionalization and bioconjugation of colloidal Inorganic nanoparticles," Philosophical Transactions of the Royal Society A: Mathematical, Physical and Engineering Sciences, vol. 368, no. 1915, pp. 1333-1383, 2010.

[3] A. M. Smith, S. Nie, and Georgia Tech and Emory University Department of Biomedical Engineering 2011, "Engineering quantum dots for live-cell single-molecule imaging," in Proceedings of the NSF Nanoscale Science and Engineering Grantees Conference, December 2011.
[4] R. Xie, U. Kolb, J. Li, T. Basché, and A. Mews, "Synthesis and characterization of highly luminescent CdSe-core CdS/ $\mathrm{Zn}_{0.5} \mathrm{Cd}_{0.5} \mathrm{~S} / \mathrm{ZnS}$ multishell nanocrystals," Journal of the American Chemical Society, vol. 127, no. 20, pp. 7480-7488, 2005.

[5] A. V. Baranov, Y. P. Rakovich, J. F. Donegan et al., "Effect of ZnS shell thickness on the phonon spectra in CdSe quantum dots," Physical Review B, vol. 68, no. 16, Article ID 165306, pp. 16530611653067, 2003.

[6] R. B. Vasiliev, S. G. Dorofeev, D. N. Dirin, D. A. Belov, and T. A. Kuznetsova, "Synthesis and optical properties of PbSe and CdSe colloidal quantum dots capped with oleic acid," Mendeleev Communications, vol. 14, no. 4, pp. 169-171, 2004.

[7] J. Yan, H. Mei, D. Li et al., "A nano- and micro- integrated protein chip based on quantum dot probes and a microfluidic network," Nano Research, vol. 1, no. 6, pp. 490-496, 2008.

[8] A. M. Dennis, D. C. Sotto, B. C. Mei, I. L. Medintz, H. Mattoussi, and G. Bao, "Surface ligand effects on metal-affinity coordination to quantum dots: implications for nanoprobe selfassembly," Bioconjugate Chemistry, vol. 21, no. 7, pp. 1160-1170, 2010.

[9] B.-K. Pong, B. L. Trout, and J.-Y. Lee, "Modified ligandexchange for efficient solubilization of CdSe/ZnS quantum dots in water: a procedure guided by computational studies," Langmuir, vol. 24, no. 10, pp. 5270-5276, 2008.

[10] T. M. Inerbaev, A. E. Masunov, S. I. Khondaker, A. Dobrinescu, A.-V. Plamad, and Y. Kawazoe, "Quantum chemistry of quantum dots: effects of ligands and oxidation," Journal of Chemical Physics, vol. 131, no. 4, Article ID 044106, 2009.

[11] I. Yildiz, B. McCaughan, S. F. Cruickshank, J. F. Callan, and F. M. Raymo, "Biocompatible CdSe-ZnS Core-shell quantum dots coated with hydrophilic polythiols," Langmuir, vol. 25, no. 12, pp. 7090-7096, 2009.

[12] A. S. Karakoti, R. Shukla, R. Shanker, and S. Singh, "Surface functionalization of quantum dots for biological applications," Advances in Colloid and Interface Science, vol. 215, pp. 28-45, 2015.

[13] J. Li and N. Wu, Biosensors Based on Nanomaterials and Nanodevices, CRC Press, New York, NY, USA, 2013.

[14] W. Luan, H. Yang, Z. Wan, B. Yuan, X. Yu, and S.-T. Tu, "Mercaptopropionic acid capped CdSe/ZnS quantum dots as fluorescence probe for lead(II)," Journal of Nanoparticle Research, vol. 14, article 762, 2012.

[15] H. Zheng, L. J. Mortensen, and L. A. DeLouise, "Thiol antioxidant-functionalized CdSe/ZnS quantum dots: synthesis, characterization, cytotoxicity," Journal of Biomedical Nanotechnology, vol. 9, no. 3, pp. 382-392, 2013.

[16] R. Tantra, P. Schulze, and P. Quincey, "Effect of nanoparticle concentration on zeta-potential measurement results and reproducibility," Particuology, vol. 8, no. 3, pp. 279-285, 2010.

[17] T. T. Ha, C. H. Chi, N. T. Vy, N. T. P. Thoa, T. D. Huynh, and Q. V. Lam, "Improving the performance of QDSSCs based on $\mathrm{Tio}_{2} / \mathrm{CdS}$ (Silar)/CdSe(Colloid)/Zns(Silar) photoanodes," Environmental Progress \& Sustainable Energy, vol. 34, no. 6, pp. 1774-1779, 2015.

[18] T. Ha Thanh, D. Huynh Thanh, and V. Quang Lam, "The $\mathrm{CdS} / \mathrm{CdSe} / \mathrm{ZnS}$ photoanode cosensitized solar cells basedon Pt, $\mathrm{CuS}, \mathrm{Cu}_{2} \mathrm{~S}$, and $\mathrm{PbS}$ counter electrodes," Advances in OptoElectronics, vol. 2014, Article ID 397681, 9 pages, 2014.

[19] N. T. Vo, H. D. Ngo, D. L. Vu, A. P. Duong, and Q. V. Lam, "Conjugation of E. coli O157:H7 antibody to CdSe/ZnS quantum dots," Journal of Nanomaterials, vol. 2015, Article ID 265315, 7 pages, 2015. 
[20] F. S. Dukhovich, M. B. Darkhovskii, E. N. Gorbatova, and V. Kurochkin, Molecular Recognition: Pharmacological Aspects, Nova Science, New York, NY, USA, 2003.

[21] Colloidal Dynamics Pty Ltd, Australian Technology Park, Sydney, Australia.

[22] W. R. Algar and U. J. Krull, "Luminescence and stability of aqueous thioalkyl acid capped $\mathrm{CdSe} / \mathrm{ZnS}$ quantum dots correlated to ligand ionization," ChemPhysChem, vol. 8, no. 4, pp. 561-568, 2007. 

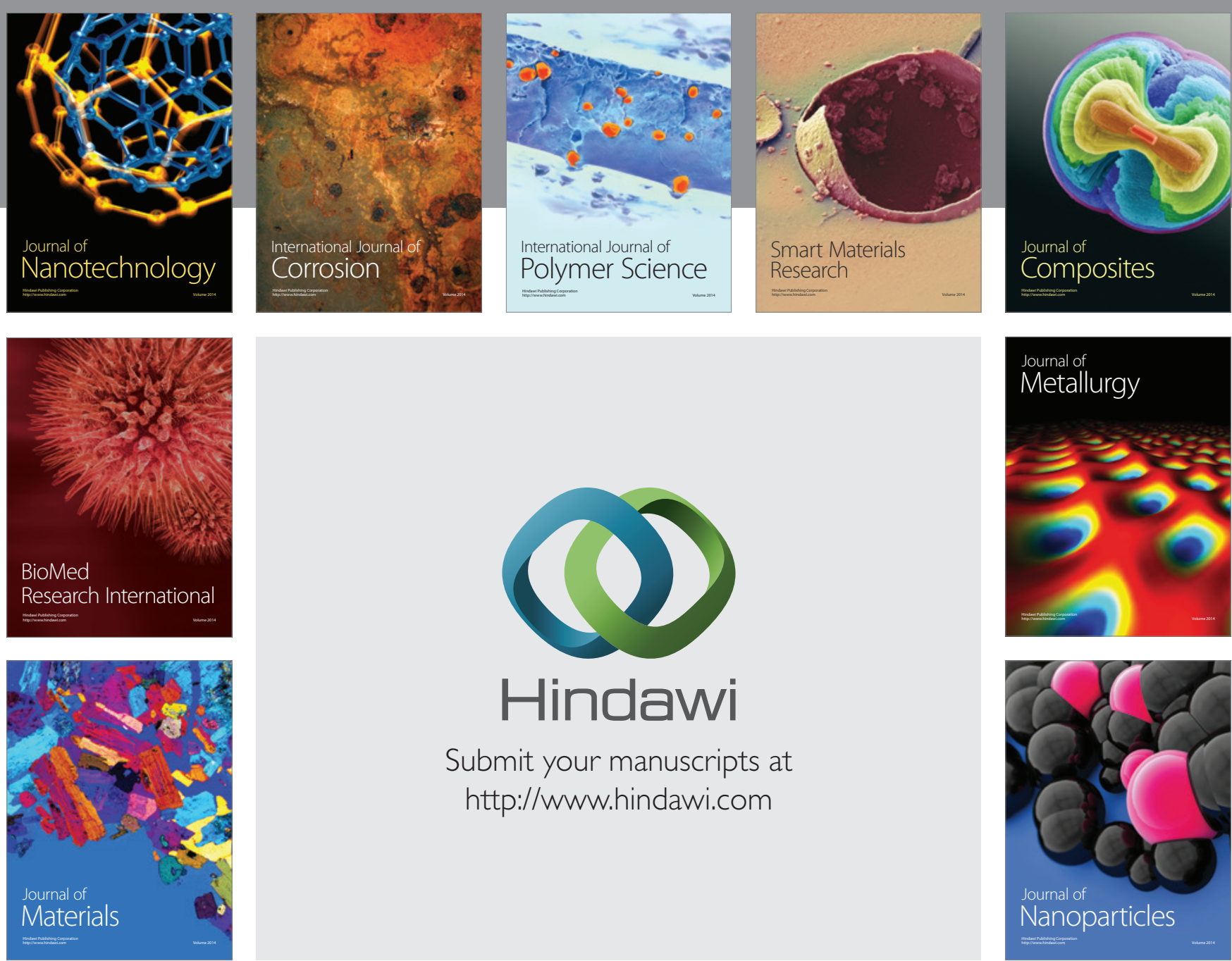

\section{Hindawi}

Submit your manuscripts at

http://www.hindawi.com

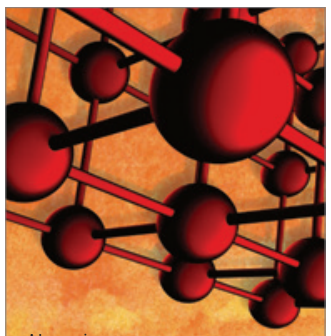

Materials Science and Engineering
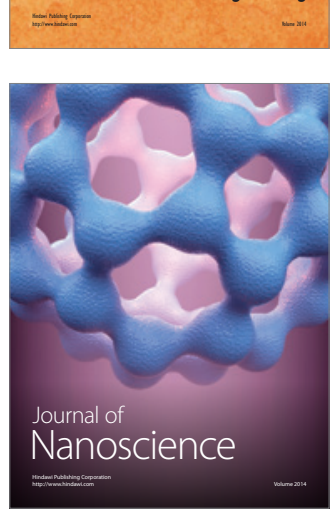
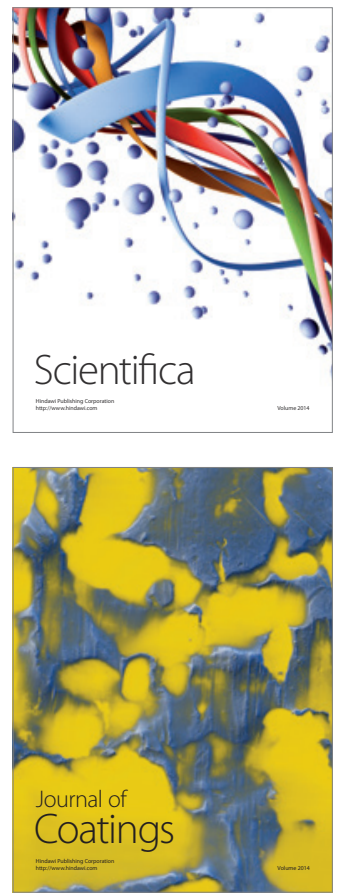
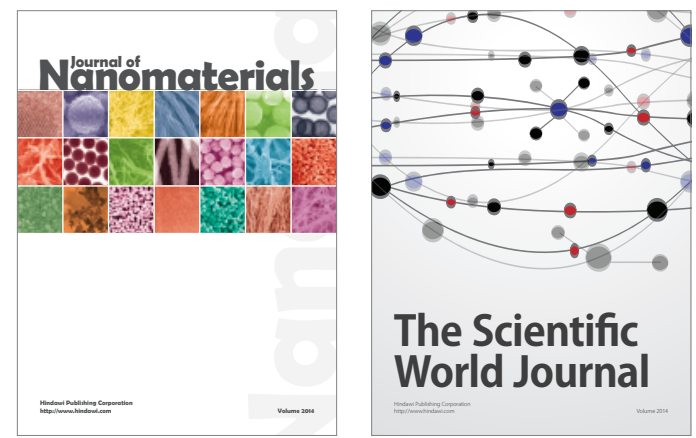

The Scientific World Journal
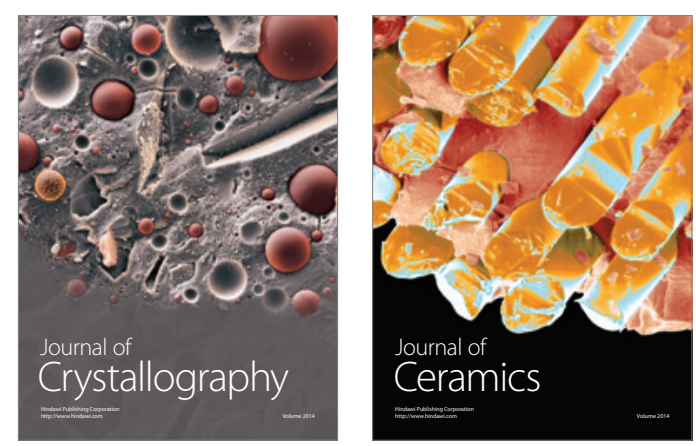
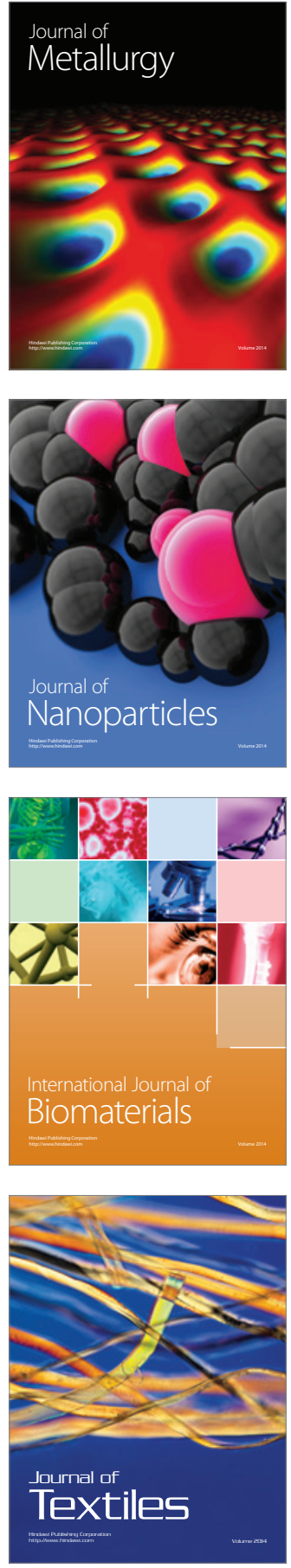